\title{
VESICULITE SEMINAL EM GARANHÕES
}

\author{
Verônica Flores da Cunha Scheeren ${ }^{1}$ \\ Thaís Mendes Sanches Cavalero ${ }^{1}$ \\ Mariana Luiza Mezzena Gobato ${ }^{1}$ \\ Lucas Emanuel Ferreira Canuto ${ }^{1}$ \\ Frederico Ozanam Papa ${ }^{2}$
}

\begin{abstract}
RESUMO
Os garanhões possuem um conjunto completo de glândulas sexuais acessórias, compostas pelas bulbouretrais, a próstata, vesículas seminais e ampolas dos ductos deferentes. Dentre as afecções que acometem essas estruturas, a vesiculite seminal é a de maior ocorrência, consistindo na colonização de uma ou ambas as vesículas por bactérias, sendo a Pseudomonas aeruginosa a mais frequente. No ejaculado é observada uma grande percentagem de neutrófilos e, eventualmente, hemácias podem estar presentes, caracterizando os quadros de piospermia e hemospermia, respectivamente. O diagnóstico definitivo é realizado por meio da endoscopia transuretral das vesículas, onde é possível visualizar o conteúdo purulento, associado à cultura bacteriana do lavado da glândula. O tratamento é desafiador, pois a antibioticoterapia apresenta baixa eficácia, com altas taxas de recidiva.
\end{abstract}

Palavras-chave: equino, infecção, vesícula seminal

\section{SEMINAL VESICULITIS IN STALLIONS}

\begin{abstract}
Stallions have a complete set of accessory sex glands, composed of the bulbourethral, prostate gland, seminal vesicles and ampullae. Among the conditions that affect these structures, seminal vesiculitis is the most common, consisting the colonization of one or both vesicles by bacteria, whose Pseudomonas aeruginosa is the most frequent. In ejaculate, a large percentage of neutrophils and, eventually, red blood cells may be present, characterizing piospermia and hemospermia, respectively. The definitive diagnosis is made through the transurethral endoscopy evaluation of the seminal vesicles, where it is possible to visualize the purulent content, associated to gland lavage and bacterial culture. Treatment is challenging because antibiotic therapy has low efficacy, with a high relapse rate.
\end{abstract}

Keywords: equine, infection, seminal vesicle.

\section{VESICULITIS SEMINAL EN PADRILLOS}

\section{RESÚMEN}

Los padrillos tienen un conjunto completo de glándulas sexuales accesorias, compuestas por las bulbouretrales, la próstata, las vesículas seminales y las ampollas del conducto deferente. Entre las condiciones que afectan estas estructuras, la vesiculitis seminal es la más común, que consiste en la colonización de una o ambas vesículas por bacterias, siendo Pseudomonas

\footnotetext{
${ }^{1}$ Departamento de Reprodução Animal e Radiologia Veterinária - FMVZ - UNESP Botucatu-SP. Correspondência: veronica_fcs@hotmail.com

2 Docente do Departamento de Reprodução Animal e Radiologia Veterinária - FMVZ - UNESP, Botucatu-SP
} 
aeruginosa la más frecuente. En la eyaculación del eyaculado, puede estar presente un gran porcentaje de neutrófilos y, eventualmente, glóbulos rojos, caracterizando la piospermia y la hemospermia, respectivamente. El diagnóstico definitivo se realiza a través de la endoscopia transuretral de las vesículas, donde es posible visualizar el contenido purulento asociado con el cultivo bacteriano del lavado de la glándula. El tratamiento es desafiante porque la terapia con antibióticos tiene baja eficácia, con altas tasas de recaída.

Palabras-clave: equino, infección, vesícula seminal.

\section{INTRODUÇÃO}

Inúmeros fatores etiológicos podem causar subfertilidade em garanhões, o que dificulta o diagnóstico. Dentre eles, a vesiculite seminal é caracterizada pela infecção bacteriana da vesícula seminal, uma das quatro glândulas sexuais acessórias do garanhão. Apesar de ser uma enfermidade pouco frequente na espécie equina, ocasiona perdas importantes e oferece um alto risco ao garanhão e às éguas envolvidas no programa reprodutivo devido à contaminação bacteriana (1). O histórico geralmente é associado com subfertilidade ou infertilidade e alterações nas características do ejaculado, como hemospermia e/ou piospermia. A alta concentração de bactérias, polimorfonucleares e hemácias no sêmen levam à diminuição da motilidade espermática, aglutinação, precipitação e aumento da produção de espécies reativas de oxigênio. Todas essas alterações afetam negativamente a qualidade e longevidade dos espermatozoides (2,3). O tratamento é desafiador devido à baixa eficiência da antibioticoterapia no controle do crescimento bacteriano e resultados inconsistentes, com altas taxas de recidiva $(4,5)$.

\section{GLÂNDULAS SEXUAIS ACESSÓRIAS NA ESPÉCIE EQUINA}

O conjunto de glândulas sexuais acessórias do garanhão inclui um par de glândulas bulbouretrais, a próstata, um par de vesículas seminais e um par de ampolas dos ductos deferentes, sendo localizadas no interior da cavidade pélvica do macho, com aberturas voltadas para o interior da uretra pélvica e dimensões que variam conforme a raça. Todas produzem secreções que irão compor o plasma seminal (6). A composição e o volume do plasma seminal variam conforme as espécies (7), assim como seus efeitos na longevidade do sêmen na espécie equina, diferenciando entre indivíduos (8).

As vesículas seminais são saculações de formato piriforme medindo de 12 a $20 \mathrm{~cm}$ de comprimento e $5 \mathrm{~cm}$ de diâmetro (9). Cada vesícula se abre no lúmen da uretra pélvica por uma dilatação da mucosa localizada dorsalmente, denominada de colículo seminal (1), onde também é o local de excreção das ampolas dos ductos deferentes (10). Em cada lado do colículo seminal há uma abertura das glândulas, podendo ser de maneira independente, ou pode haver uma união destes, formando um ducto comum, denominado de ducto ejaculatório. Logo, podem estar presentes quatro ou duas aberturas no colículo seminal, respectivamente (11).

Tanto a estrutura quanto as características histológicas da vesícula seminal variam entre as espécies. No bovino, são compactas e lobuladas (12), e possuem epitélio pseudoestratificado, no qual as glândulas tubuloalveolares são separadas por abundante musculatura lisa (13). No equino, as vesículas apresentam epitélio colunar estratificado, separado por um delgado tecido conjuntivo e vasos de diferentes calibres ao redor (14).

Pelo exame transretal é difícil palpar as vesículas seminais (11), assim como identificálas pela ultrassonografia, quando estão desprovidas de fluído (15). O tamanho e a quantidade de conteúdo no interior das glândulas acessórias são afetados diretamente pelo grau de 
estímulo sexual do garanhão e intervalo de tempo entre a última ejaculação e o exame (16). Monteiro (9) mostrou que após estimulação sexual há alterações no tamanho, forma e aparência ultrassonográfica de todas as glândulas.

A vesícula seminal de um garanhão sadio em repouso possui aparência ultrassonográfica homogênea, as paredes musculares permanecem achatadas dorsoventralmente, sendo mais hiperecóicas que os tecidos adjacentes, e quantidades variáveis de fluído podem ser observadas (17). Após a excitação, há aumento da quantidade de líquido no lúmen, as vesículas se distendem e adotam formato mais arredondado. O fluído geralmente é anecóico (18), mas foram observadas variações na ecogenicidade do conteúdo entre garanhões (16).

As secreções produzidas pelas glândulas sexuais acessórias e pelos epidídimos constituem a porção fluida do sêmen, o plasma seminal, que junto dos espermatozoides, constituem o ejaculado. As vesículas seminais são responsáveis pela fração gel do ejaculado, sendo a última a ser liberada no processo ejaculatório no garanhão, rica em ácido lático e cítrico (19), cujo volume varia entre garanhões (20) e a sazonalidade (16). Também estão presentes na secreção das vesículas seminais algumas enzimas, como as glicosidases, envolvidas nas alterações espermáticas que antecedem a fertilização, e três tipos de anidrase carbônica, relacionadas à regulação do pH seminal e concentração de bicarbonato.

Em meio às proteínas presentes no plasma seminal, a proteína rica em Cisteína Tipo III (CRISP-3) é produzida pelas glândulas vesiculares (19). Segundo Troedsson et al. (21) essa proteína possui a função de proteger os espermatozoides vivos da ação por polimorfonucleares, permitindo sua sobrevivência e chegada até a tuba uterina.

\section{VESICULITE SEMINAL}

Dentre as afecções envolvendo as glândulas sexuais acessórias em equinos, a vesiculite seminal é a mais frequente (22). Consiste na colonização de uma ou ambas vesículas por bactérias, nas quais há acumulo de conteúdo purulento no interior da(s) glândula(s), que pode ser excretado no sêmen durante a ejaculação (23).

Esta alteração se caracteriza por inflamação difusa da vesícula, causando alterações físico-químicas no sêmen e, em alguns casos, distúrbios ejaculatórios. Isso leva a redução da longevidade e fertilidade do sêmen, classificando o animal acometido como impróprio à atividade reprodutiva, por se tornar disseminador de patógenos transmissíveis sexualmente (24).

A porção distal da uretra e o pênis são fisiologicamente colonizados por uma população de bactérias não patogênicas, que representam a microbiota normal (25), sendo estas Escheria coli, Pseudomonas aeruginosa, Streptococcus alfa, beta, e não hemolítico, Klebsiella pneumoniae, Staphylococcus spp., Corynebacterium, Proteus spp., Bacillus spp. (26,27). Os fatores que predispõem a colonização do pênis não estão esclarecidos, porém é sabido que a lavagem e a desinfecção do órgão estão associadas à remoção da microbiota comensal, favorecendo o crescimento de bactérias oportunistas como a $P$. aeruginosa e $K$. pneumoniae $(28,29)$.

Quando as bactérias estão presentes em outras regiões do trato reprodutivo, caracterizam uma alteração (25). Apesar de pouco comum em garanhões, a vesiculite seminal assume importante papel pelo seu caráter persistente e de difícil tratamento (1). Além do mais, o risco de transmissão venérea é alto, assim como os efeitos deletérios na qualidade seminal e fertilidade (30).

\section{Etiopatogenia}


Dentre as bactérias encontradas colonizando a vesícula seminal estão Staphylococcus spp., Streptococcus spp., E.coli e P. vulgaris (30,31), sendo a P. aeruginosa e K. pneumoniae as mais frequentes $(29,32,33)$. Há relatos de vesiculite seminal por Brucella abortus e Acinetobacter calcoaceticus, apesar de pouco frequentes (1,3).

Outros agentes etiológicos como protozoários, vírus, clamídia, micoplasma e ureaplasma podem estar associados com o desenvolvimento de vesiculite seminal em outras espécies, assim como em humanos (34), porém em equinos esses microorganismos nunca foram isolados nas vesículas seminais de garanhões com a enfermidade (3).

$P$. aeruginosa é uma bactéria oportunista, Gram-negativa, aeróbia e formadora de biofilme, sendo responsável por infecções em diversos sistemas do organismo, tanto em humanos quanto em animais. Possui um especializado quorum sensing, capaz de debelar o sistema imune do hospedeiro (35). É multirresistente aos antimicrobianos disponíveis e está desenvolvendo resistência aos fármacos mais modernos, como o imipenem (36).

E. coli e K. pneumoniae são bactérias Gram-negativas, aeróbia ou anaeróbia facultativa, respectivamente. Assim como a $P$. aeruginosa, são multirresistentes aos antibióticos disponíveis, estando envolvidas em casos de pacientes septicêmicos (37).

A patogenia desta infecção permanece desconhecida (38), todavia acredita-se que existam potenciais rotas de contaminação, que são por via ascendente pela uretra, da via descendente pelo trato urinário, da via hematógena e linfática ou pela invasão direta do tecido periglandular (3).

\section{Sinais clínicos}

Na maioria dos casos, os garanhões acometidos pela vesiculite seminal não demonstram sinais clínicos, se apresentam sem hipertermia e nenhuma alteração nos parâmetros vitais. Geralmente os animais não manifestam dor durante a micção, defecação ou cópula (3). Todavia, algumas alterações são relatadas em poucos animais, como disfunção ejaculatória, evidenciando dor no momento da ejaculação, o que pode tornar o garanhão relutante a realizar coberturas (23). Freestone et al. (39) relataram um caso de um garanhão que apresentou sinais de cólica por um período de quatro meses em decorrência de vesiculite unilateral. Ainda, McDonnell (40) observou que a infecção da glândula pode induzir ao comportamento de auto-mutilação, como rolar, pinotear, escoicear o abdômen, morder e olhar para o flanco.

A suspeita da enfermidade geralmente ocorre quando há histórico de subfertilidade ou infertilidade, associado com alterações nas características do ejaculado (30). O sêmen de um garanhão saudável apresenta coloração branca ou branco-acinzentada (22) e quando acometido pela vesiculite a coloração pode variar de amarelado a avermelhado devido ao conteúdo purulento e sangue (Figura 1-A), denominados de piospermia e hemospermia, respectivamente (3).

Pelo exame citológico do sêmen, podem ser identificadas quantidade variável de polimorfonucleares e bactérias (Figura 1-B). O sêmen logo após a ejaculação pode apresentar boa qualidade, porém a longevidade geralmente é reduzida (1). Isso se deve, principalmente, à presença de neutrófilos que induzem a precipitação e aglutinação das células, afetando negativamente a cinética espermática (23). 


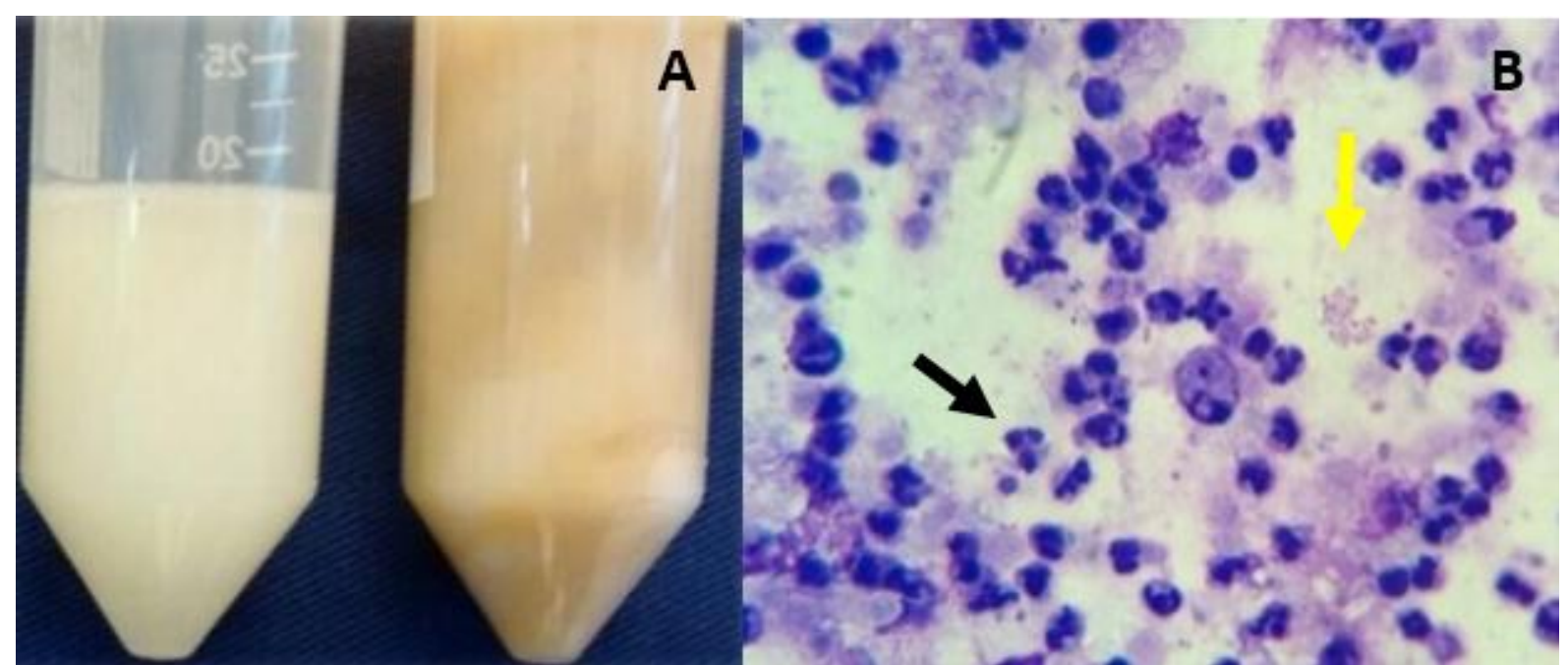

Figura 1. À esquerda, ejaculado apresentando coloração branca (normospermia) e à direita, ejaculado com característica purulenta (piospermia) (A). Citologia de ejaculado apresentando bactérias (seta amarela) e grande quantidade de neutrófilos (seta preta) (B) (Arquivo pessoal).

Os efeitos provocados pelos neutrófilos no sêmen estão relacionados com o aumento da produção de espécies reativas de oxigênio (EROs), uma vez que os leucócitos são capazes de produzir EROs cem vezes mais que os espermatozoides (2). As EROs possuem efeito prejudicial às células espermáticas, como lesões na membrana plasmática, capacitação precoce, fragmentação do DNA e injúrias mitocondriais. Ainda, as bactérias presentes no sêmen, junto das ROS, podem induzir à apoptose espermática (34).

\section{Diagnóstico}

O diagnóstico presuntivo da vesiculite seminal é feito após as análises macro e microscópicas do sêmen. Para determinar a origem dos neutrófilos presentes no ejaculado deve-se examinar todo o trato reprodutivo, pois essas células podem ter origem de lesões penianas, da uretra ou do trato urinário (1).

A cultura e isolamento de bactérias do pênis, uretra e sêmen devem ser realizadas. Garanhões com suspeita de vesiculite seminal possuem uma microbiota potencialmente patogênica no pênis e prepúcio (41). O sêmen deve ser coletado de forma higiênica, prevenindo contaminação iatrogênica. $\mathrm{O}$ crescimento massivo e isolado de uma bactéria em todas as amostras é consistente com infecção do trato reprodutivo interno (3).

Ainda, outra técnica de auxílio diagnóstico para identificar a fonte contaminação do sêmen é a coleta fracionada (23). Por este método é feita a separação do sêmen em fração rica em espermatozoides (primeiros dois a três jatos) e fração pobre (jatos posteriores) (42). Mediante a visualização, citologia e cultura de cada fração é sugestivo um quadro de vesiculite seminal ou ampulite, porém sem especificar o local exato da infecção (29). A principal vantagem é que esta é uma técnica não invasiva e que permite o diagnóstico presuntivo desta enfermidade.

\section{Palpação e exame ultrassonográfico}

O exame dos órgãos genitais internos pode ser realizado pela palpação e ultrassonografia transretal. É imprescindível uma adequada contenção do garanhão para que 
se proceda o exame, e a sedação ou tranquilização podem ser necessárias em garanhões nervosos (43).

Dentre as alterações encontradas na palpação retal em garanhões com vesiculite seminal o aumento de tamanho é o mais frequente, seguido por consistência firme $(31,33)$ e sensibilidade ao toque nas vesículas seminais (39). As glândulas podem se apresentar com característica lobulada, no entanto, a palpação geralmente não fornece informações diagnósticas suficientes. Alterações no tamanho, forma e consistência podem não ser observadas, o que não exclui a presença da infecção $(1,4)$.

Em garanhões acometidos por essa enfermidade, pode ser observado no exame ultrassonográfico um espessamento da parede da glândula e o conteúdo em seu interior é de caráter hiperecogênico (33), ou conteúdo anecóico, de característica normal (10). O acúmulo de conteúdo purulento é visto pelo aumento de tamanho do lúmen glandular em corte transversal e variações na ecogenicidade e presença de floculações no líquido, representadas por pontos hiperecogênicos $(20,27)$. Em casos crônicos, as vesículas podem se tornar firmes, diminuídas e sem conteúdo (30).

Alterações no tamanho e característica do conteúdo entre as vesículas seminais de um mesmo garanhão e entre garanhões foram observadas por Pozor e McDonnell (16). Alguns animais, sabidamente saudáveis, apresentaram aumento da ecogenicidade no lúmen glandular, sugerindo que não necessariamente a hiperecogenicidade indica infecção. Os autores ainda sugerem que as alterações possam estar relacionadas à estação do ano e intervalo de coleta de sêmen, previamente ao exame.

Embora em alguns casos a ultrassonografia não revele alterações decorrentes de vesiculite, esta deve ser utilizada no exame andrológico (10). Essa ferramenta auxilia no diagnóstico da vesiculite seminal, porém não é crucial já que existem inúmeras variações no mesmo e entre animais (44).

\section{Exame endoscópico}

O diagnóstico definitivo da vesiculite seminal é feito pela endoscopia das vesículas seminais (1). Utilizando o equipamento é possível acessar as glândulas, colher material para cultura e antibiograma e infundir medicamentos e/ou substâncias em seu interior mediante a cateterização dos ductos ejaculatórios (23).

Para realização do exame é necessário um fibroscópio ou videoendoscópio flexível, de no mínimo $100 \mathrm{~cm}$ de comprimento e diâmetro de no máximo $10 \mathrm{~mm}$. Para garanhões de grande porte, um endoscópio mais longo é necessário para acesso das vesículas, assim como um endoscópio mais fino para animais de pequeno porte. Cateter de polietileno, pinça de biopsia, solução fisiológica, seringa e tubos estéreis são necessários para coleta de material e envio para cultura (45).

Com o animal sedado é feita a higienização do pênis, o endoscópio é inserido na uretra peniana, progredindo até que se alcance a uretra pélvica e sejam visualizadas as aberturas as glândulas sexuais acessórias. Dentre as quatro glândulas sexuais acessórias, apenas a vesícula seminal é passível de ser acessada, por conter um lúmen amplo e complacente (6).

$\mathrm{O}$ acesso a cada vesícula seminal é feito pela cateterização do seu ducto na abertura no colículo seminal, passando um cateter pelo canal de biópsia do endoscópio. O lúmen é inspecionado e pode se observar o acúmulo de conteúdo purulento (Figura 2), erosões no epitélio da vesícula (31), e quantidade variáveis de sangue (38).

Amostras do interior da glândula podem ser colhidas para citologia e cultura (45), e biopsia para exame histopatológico do epitélio (14). Com base nos resultados encontrados é confirmado o diagnóstico de vesiculite seminal (6). 


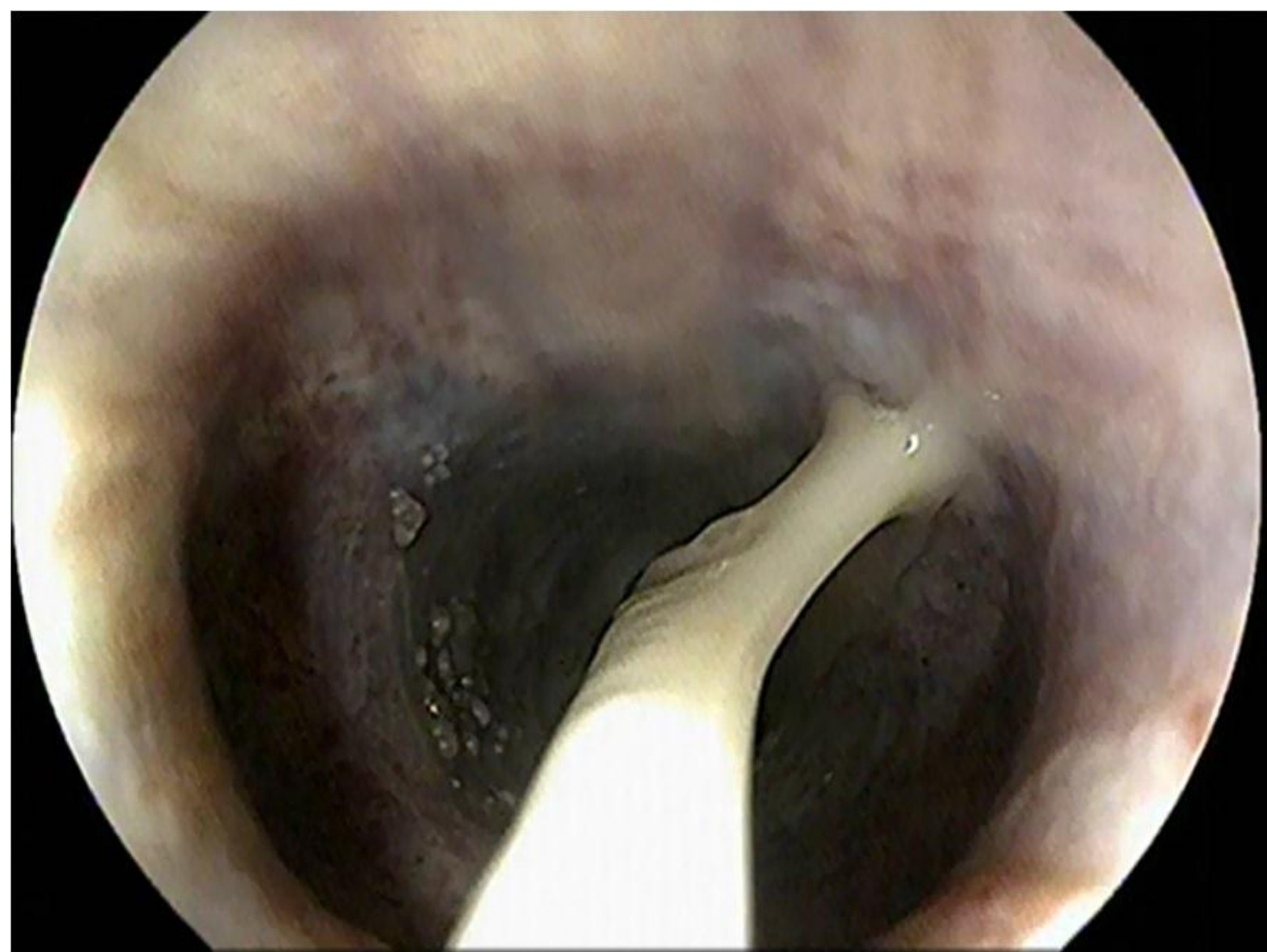

Figura 2. Imagem endoscópica da vesícula seminal apresentando conteúdo purulento em seu interior (Arquivo pessoal).

\section{Tratamento}

O tratamento da vesiculite seminal geralmente é difícil e sem sucesso, sendo relatado por vários autores $(4,32,33)$, evoluindo para uma condição crônica (32). A efetividade no tratamento é pouco relatada (3,31). A dificuldade se deve a características de farmacodinâmica e farmacocinética dos medicamentos disponíveis. A maioria dos antimicrobianos utilizados não alcança a glândula em concentrações adequadas para serem efetivos (30). O antibiótico escolhido deve possuir alguns atributos para chegar no interior da vesícula, como: alto pKa e alta solubilidade em lipídeos (38), baixa massa molecular e afinidade de ligação a proteínas plasmáticas (46).

O tratamento antimicrobiano em garanhões leva em consideração, além das características mencionadas acima, à sensibilidade da bactéria na escolha do antibiótico utilizado. De modo geral, os fármacos que possuem melhor penetração na vesícula seminal são a enrofloxacina e sulfonamida-trimetropim (3), por outro lado, a gentamicina se mostra incapaz de penetrar nas vesículas seminais de garanhões (32).

Estudos posteriores relatam sucesso com a utilização de sulfonamida-trimetropin (39) e enrofloxacina (47) via sistêmica. A utilização de penicilina procaína também se mostrou efetiva em alguns garanhões (4). Entretanto, Blanchard et al. (47) relataram um caso em que o tratamento com enrofloxacina não foi eficaz para combater a vesiculite seminal por Acinetobacter calcoaceticus.

Outra opção terapêutica é a infusão local do antimicrobiano na vesícula seminal. Segundo Miragaya et al. (5) esta é a técnica de eleição para tratamento da enfermidade, via endoscopia. Inicialmente, as vesículas seminais são lavadas com um alto volume de solução fisiológica, para remover o conteúdo purulento e debris no interior da glândula. Em seguida, o 
antibiótico é instilado diretamente no lúmen. Essas aplicações devem ser repetidas por no mínimo cinco dias consecutivos (23).

Recentemente, Pinto et al. (31) relataram um caso de sucesso no tratamento de um garanhão com vesiculite seminal por Klebsiella pneumoniae, utilizando imipenem-cilastatina local. Entretanto, em outro estudo, a antibioticoterapia local guiada por endoscópio em cinco garanhões mostrou eficácia temporária, com recidiva 30 dias após o final do tratamento em todos os indivíduos testados (24).

Existe ainda a associação das terapias local e parenteral, relatadas por alguns autores. Gay e Perrini (48) utilizaram a sulfonamida-trimetropin via oral com infusão local de amicacina, com melhora clínica na infecção causada por P. vulgaris. Já Fennell et al. (40) realizaram a administração de sulfonamida-trimetropin via oral e infusão local de penicilina procaína em vesiculite causada por Streptococcus spp., resultando em melhora clínica, permitindo a congelação de sêmen. Porém, o garanhão apresentou piospermia aproximadamente 21 dias após o término do tratamento.

Alguns autores relatam a vesiculectomia seminal como método terapêutico em equinos (49), todavia é considerada radical e não tem sido utilizada rotineiramente (5). Existem inúmeras complicações trans e pós-operatórias, que incluem o difícil acesso às vesículas, hemorragia, lesão em nervos ou musculatura e infecção, que predispõem à disfunção ejaculatória (3). Apenas um relato de sucesso existe na literatura, no qual a técnica utilizada para vesiculectomia foi a mesma utilizada em touros (50).

\section{Prognóstico}

O prognóstico reprodutivo da vesiculite seminal é reservado, devido à ineficácia da antibioticoterapia e alta taxa de recorrência $(23,24)$. Muitas vezes, a vesiculite está relacionada a infecção de outras porções do trato reprodutivo, sendo os testículos e epidídimos os mais afetados, provocando orquite e epididimite (31). Além dessas estruturas, as ampolas também podem ser acometidas, causando ampulite $(32,51)$.

Em todos os relatos, a infecção dos demais órgãos foi por via ascendente e com resoluções distintas. Pinto et al. (31) após o tratamento sistêmico e local conseguiram controlar a infecção e obtiveram melhora clínica do garanhão. Enquanto que como resultado de Comeford et al. (51), o garanhão não conseguiu eliminar a infecção testicular após diversas tentativas de tratamento, sendo submetido a orquiectomia bilateral.

\section{CONSIDERAÇÕES FINAIS}

A vesiculite seminal é uma alteração grave e de difícil tratamento, que pode levar ao afastamento do garanhão de sua vida reprodutiva. Infecções concomitantes, como a orquite e epididimite, podem afetar drasticamente a fertilidade do garanhão. $\mathrm{O}$ exame endoscópico é uma importante ferramenta para confirmação do diagnóstico de vesiculite seminal, porém exige cautela em sua realização, pelo risco de contaminação iatrogênica de outras porções do trato reprodutivo.

\section{REFERÊNCIAS}

1. Varner DD, Blanchard TL, Brinsko SP, Love CC, Taylor TS, Johnson L. Techniques for evaluating selected reproductive disorders of stallions. Anim Reprod Sci. 2000;60-61:493509. 
2. Baumber JVOA, Sabeur K, Ball BA. Generation of reactive oxygen species by equine neutrophils and their effect on motility of equine spermatozoa. Theriogenology. 2002;57:1025-33.

3. Varner DD, Schumacher J. Abnormalities of the accessory sex glands. In: McKinnon AO, Squires EL, Vaala WE, Varner DD. Equine reproduction. 2nd. Hoboken: Wiley-Blackwell, 2011. p.867-80.

4. Fennel LC, McKinnon AO, Savage CJ. Cryopreservation of semen from a stallion with seminal vesiculitis. Equine Vet Educ. 2010;22:215-9.

5. Miragaya MH, Pinto MR, Neild DM. Muestreo y lavage de glândulas vesiculares en el padrillo. In: Proceedings of 2nd Congress on Equine Reproduction; 2011; Medonza, AR. Medonza; 2011. p.71-2.

6. Tibary A. Endoscopy of the reproductive tract in the stallion. In: Samper JC, Pycock JF, McKinnon AO. Current therapy in equine reproduction. Philadelphia: Saunders; 2007. p.214-9.

7. Hafez ESSE, Hafez B. Reprodução animal. 7a ed. São Paulo: Manole; 2004.

8. Kareskoski M, Katila T. Components of stallion seminal plasma and the effects of seminal plasma on sperm longevity. Anim Reprod Sci. 2008;107:249-56.

9. Monteiro GA. Ultrassonografia aplicada ao exame andrológico em garanhões. Rev Bras Reprod Anim. 2017;41:157-68.

10. Ball BA. Diagnostic methods for evaluation of stallion subfertility: a review. J Equine Vet Sci. 2008;28:650-5.

11. Chenier TS. Anatomy and physical examination of the stallion. In: Samper JC. Equine breeding management and artificial insemination. 2nd ed. Philadelphia: Saunders; 2009. p.1-16.

12. Blanchard TL, Varner DD, Bretzlaff KN. Seminal vesiculitis. In: Smith BP. Large animal internal medicine. 2nd ed. St. Louis: Mosby; 2001. p.1574-5.

13. Bacha WJ, Bacha LM. Atlas colorido de histologia veterinária. 2a ed. São Paulo: Roca; 2003.

14. Scheeren VFC, Gobato MLM, Papa PM, Cavalero TMS, Canuto LEF, Rodrigues LT, et al. The use of endoscopic biopsy to compare histological finds of stallions with and without seminal vesiculitis. J Equine Vet Sci. 2018;66:50.

15. Weber JA, Woods GL. Transrectal ultrasonography for the evaluation of stallion accessory sex glands. Vet Clin North Am Equine Pract. 1993;8:183-90.

16. Pozor MA, McDonnell SM. Ultrasonographic measurements of accessory sex glands, ampullae, and urethra of normal stallions of various size types. Theriogenology. 2002;58:1425-33. 
17. Turner RMO. How to perform an examination of the internal reproductive tract of the stallion. In: Proceedings of the 60th AAEP Annual Convention; 2014; Salt Lake City. Salt Lake City: AAEP; 2014. p.294-301.

18. Monteiro GA, Guasti PN, Melo CM, Martin JC, DellAqua Júnior JA, Alvarenga MA, et al. Comparison between cryopreservation of stallion semen obtained from ejaculate and epididymis cauda In: Proceedings of 11th Congress of the World Equine Veterinary Association - WEVA; 2009; Guarujá. Guarujá: WEVA; 2009. p.297.

19. Kareskoski M. Components of fractionated stallion seminal plasma and the effects of seminal plasma on sperm longevity [PhD thesis]. Helsinki, Finland: Faculty of Veterinary Medicine, University of Helsinki; 2011.

20. Mancill SS. Clinical and sub-clinical seminal vesiculitis in the stallion. Equine Vet Educ. 2010;22:220-2.

21. Troedsson MHT, Doty A, Macpherson ML, Connor MC, Verstegen JP, Pozor MA, et al. CRISP-3 in equine seminal plasma is involved in selective uterine sperm transport. Anim Reprod Sci. 2010;121:192-3.

22. Tibary A, Rodriguez JS, Samper JC. Microbiology and diseases of semen. In: Samper JC. Equine breeding management and artificial insemination. 2nd ed. Philadelphia: Saunders; 2009. p.99-112.

23. Tibary A, Rodriguez JS. Causas e manejo de lãs subfertilidad em padrillos. In: Proceedings of 2nd Congresso on Equine Reproduction; 2011; Mendonza, AR. Mendonza; 2011. p.55-69.

24. Sancler-Silva YFR. Efeito do tratamento local de vesiculite seminal sobre a qualidade e longevidade do sêmen equino [dissertação]. Botucatu: Faculdade de Medicina Veterinária e Zootecnia, Universidade Estadual Paulista; 2014.

25. Rota A, Calicchio E, Nardoni S, Fratini F, Ebani VV, Sgorbini M, et al. Presence and distribution of fungi and bacteria in the reproductive tract of healthy stallions. Theriogenology. 2011;76:464-70.

26. Pickett BW, Voss JL, Jones RL. Control of bacteria in stallions and their semen. J Equine Vet Sci. 1999;19:424-69.

27. Edwars JF. Pathologic conditions of the stallion reproductive tract. Anim Reprod Sci. 2008;107:197-207.

28. Bowen JM, Tobin N, Simpson RB, Ley WB, Ansari MM. Effects of washing on the bacterial flora of the stallion's penis. J Reprod Fertil Suppl. 1982;32:41-5.

29. Lu KG, Morresey PP. Reproductive tract infections in horses. Vet Clin North Am Equine Pract. 2006;22:519-52.

30. Samper J, Tibary A. Disease transmission in horses. Theriogenology. 2006;66:551-9. 
31. Pinto MR, Neild DM, Benegas D, Vieyra DH, Miragaya MH. Successful treatment of seminal vesiculitis with imipenem-cilastatin in a stallion. J Equine Vet Sci. 2014;34:5448 .

32. Blanchard TL, Varner DD, Hurtgen JP, Love CC, Cummings MR, Strezmienski PJ, et al. Bilateral seminal vesiculitis and ampullitis in a stallion. J Am Vet Med Assoc. 1988;192:525-6.

33. Malmgren L, Sussemilch BI. Ultrasonography as a diagnostic tool in a stallion with seminal vesiculitis: a case report. Theriogenology. 1992;37:935-8.

34. Vignera S, Vicari E, Condorelli RA, D'Agata R, Calogero DAE. Male accessory gland infection and sperm parameters (review). Int J Androl. 2011;34:330-47.

35. Kariminik A, Baseri-salehi M, Kheirkhah B. Pseudomonas aeruginosa quorum sensing modulates immune responses: an update review article. Immunol Lett. 2017;190:1-6.

36. He J, Jia X, Yang S, Xu X, Sun K, Li C, Yang T, Zhang L. Heteroresistance to carbapenems in invasive Pseudomonas aeruginosa infections. Int $\mathrm{J}$ Antimicrob Agents. 2018;51:413-21.

37. Stoesser N, Batty EM, Eyre DW, Morgan M, Wyllie DH, Del Ojo Elias C, et al. Predicting antimicrobial susceptibilities for Escherichia coli and Klebsiella pneumoniae isolates using whole genomic sequence data. J Antimicrobial Chemother. 2013;68:223444.

38. Pearson LK, Campbell AJ, Tibary A. How to diagnose and treat hemospermia: a review and case series. In: Proceedings of the 59th AAEP Annual Convention; 2013; Nashville. Nashville: AAEP; 2013. p.40-50.

39. Freestone JF, Paccamonti DL, Eilts BE, McClure JJ, Swiderski CE, Causey RC. Seminal vesiculitis as a cause of signs of colic in a stallion. J Am Vet Med Assoc. 1993;15:556-7.

40. McDonnel SM. Practical review of self-mutilation in horses. Anim Reprod Sci. 2008;107:219-28.

41. Varner DD. Approaches to breeding soundness examination and interpretations of results. J Equine Vet Sci. 2016;43:37-44.

42. Oliveira SN, Araujo EAB, Silva LFMC, Dalanezi FM, Papa PM, Pinto BM, et al. Colheita fracionada e seus principais benefícios na criopreservação do sêmen de garanhões. Vet Zootec. 2017;24:435-43.

43. Brinsko SP, Blanchard TL, Varner DD, Schumacher J, Love CC, Hinrichs K, et al. Manual of equine reproduction. 3rd ed. Maryland Heights: Mosby; 2011.

44. Pozor MA. Diagnostic applications of ultrasonography to stallion's reproductive tract. Theriogenology. 2005;64:505-9. 
45. Varner DD. How to perform urethral endoscopy in the stallion for diagnostic purposes. In: Proceedings of the 60th AAEP Annual Convention; 2014; Salt Lake City. Salt Lake City: AAEP; 2014. p.309-15.

46. Wagenlehner FME, Weidner W, Sorgel F, Naber KG. The role of antibiotics in chronic bacterial prostatitis. Int J Antimicrob Agents. 2005;26:1-7.

47. Blanchard TL, Woods JA, Brinsko SP, Varner DD, Boothe DM. Theriogenology question of the month. Treatment options for erosive seminal vesiculitis caused by Acinetobacter calcoaceticus. J Am Vet Med Assoc. 2002;15:221-6.

48. Gay Y, Perrin R. Deux cas d étalons présentant une vésiculite. Pract Vet Equine. 1999;31:57-60.

49. Klug E, Deegen E, Liesk R, Freytag K, Martin JC, Gunzel AR, et al. The effect of vesiculectomy on seminal characteristics in the stallion. J Reprod Fertil Suppl. 1979;27:61-6.

50. Deegen E, Klug E, Lieske R. Surgical treatment of chronic purulent seminal vesiculitis in the stallion. Dtshe Tierarztl Wochensch. 1979;86:140-4.

51. Comerford KL, Voge JL, Love CC, Varner DD. Epididymitis, ampullitis and periorchitis due to an ascending seminal vesiculitis caused by Pseudomonas aeruginosa in as stallion. Clin Theriogenol. 2011;3:366.

Recebido em: 20/08/2019

Aceito em: 30/11/2020 